\title{
Primary Thyroid Lymphoma as A Manifestation of Rapidly Growing Thyroid Causing Progressive Respiratory Distress
}

\author{
Chisho Hoshino ${ }^{\mathrm{a}, \mathrm{b}}$, Akane Yamabe ${ }^{\mathrm{a}}$, Yoshiyuki Sekikawa ${ }^{\mathrm{a}}$, Kana Ishihara ${ }^{\mathrm{a}}$, \\ Hiroshi Ikeda ${ }^{a}$, Masashi Narita ${ }^{a}$, Minoru Inoue ${ }^{a}$
}

\begin{abstract}
The author present a 73-year old man with rapidly glowing neck mass. He had a 6-year history of hypothyroidism-associated with Hashimoto thyroiditis and maintained L-thyroxine replacement. He had noticed progressive dyspnea with rapid enlargement of the thyroid grand over a month. An incisional biopsy of the thyroid grand for combined pathology and immunohistochemistry revealed diffuse large B cell non-Hodgkin's lymphoma with germinal center B-cell subtype. Primary thyroid lymphoma requires prompt diagnosis because of its ability to cause progressive compression symptoms. An incisional biopsy of the thyroid grand is required for combined pathology and immunohistochemistry. Combination chemotherapy can dramatically shrink the tumor and briefly resolve the compression symptoms.
\end{abstract}

Keywords: Primary thyroid lymphoma; Hashimoto thyroiditis; A diffuse large B cell non-Hodgkin's lymphoma; Respiratory distress; Immunohistochemistry; Combination chemotherapy

\section{Introduction}

Malignant thyroid tumors are predominantly follicular epithelial-derived, which are divided into three categories such as papillary cancer, follicular cancer, and anaplastic cancer [1-2]. non-Hodgkin's lymphoma (NHL) most frequently arise from lymph nodes, while $10-30 \%$ of cases originate from extranodal sites [3] and the thyroid grand can

Manuscript accepted for publication October 5, 2011

${ }^{a}$ Ohta-Nishinouchi Hospital, General Internal Medicine, 2-5-20

Nishinouchi, Koriyama City, Fukushima-ken, Japan

${ }^{\mathrm{b}}$ Corresponding author: Chisho Hoshino.

Email: chisho@muc.biglobe.ne.jp be an important primary source of NHL, accounting for 1 $5 \%$ of all thyroid malignancies and $1-2.5 \%$ of all lymphomas [4]. We report a diffuse large B cell NHL (DLBCL) of the thyroid grand case, presenting as rapidly growing thyroid with progressive compression symptoms. We hope this case report will aid clinicians in the management for such a patient.

\section{Case Report}

A 73-year-old man presented to our hospital complaining of rapidly growing mass in the anterior neck and progressive dyspnea of one month duration. He had no systemic symptoms, including fever, night sweats and weight loss. He had a 6-year history of hypothyroidism-associated with Hashimoto thyroiditis (HT) and maintained L-thyroxine replacement. On physical examination, a large mass was evident in the anterior neck (Fig. 1). On palpation, it was an elastic hard, immobile, and nontender mass and the exact border was ill-defined. No superficial lymph node was palpable. The respiratory sound slightly decreased with prolonged expiration bilaterally. On the laboratory, a leucocyte count of $6.1 \times 10^{4} / \mu \mathrm{L}$, hemoglobin $15.2 \mathrm{~g} / \mathrm{dL}$, platelet count $26.4 \times 10^{4} / \mu \mathrm{L}$, lactate dehydrogenase $289 \mathrm{IU} / \mathrm{L}$ (110 - 220), soluble IL-2 receptor $2040 \mathrm{U} / \mathrm{mL}$ (145 - 519). The thyroid function was as followed: thyroid-stimulating hormone $11.0 \mathrm{mIU} / \mathrm{L}\left(0.46\right.$ - 3.7), free $\mathrm{T}_{3} 2.15 \mathrm{pg} / \mathrm{mL}(1.45$

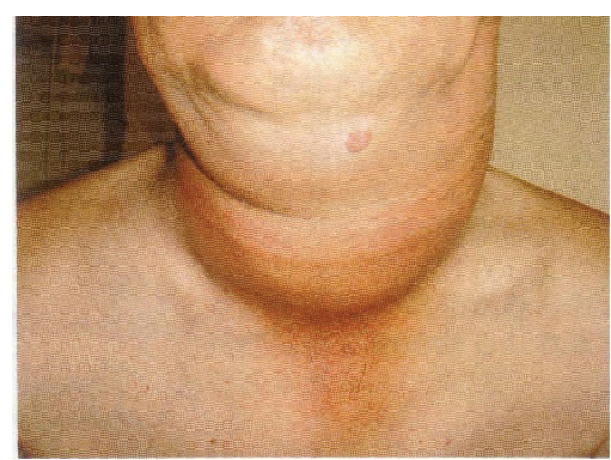

Figure 1. A large mass was evident in the anterior neck. 

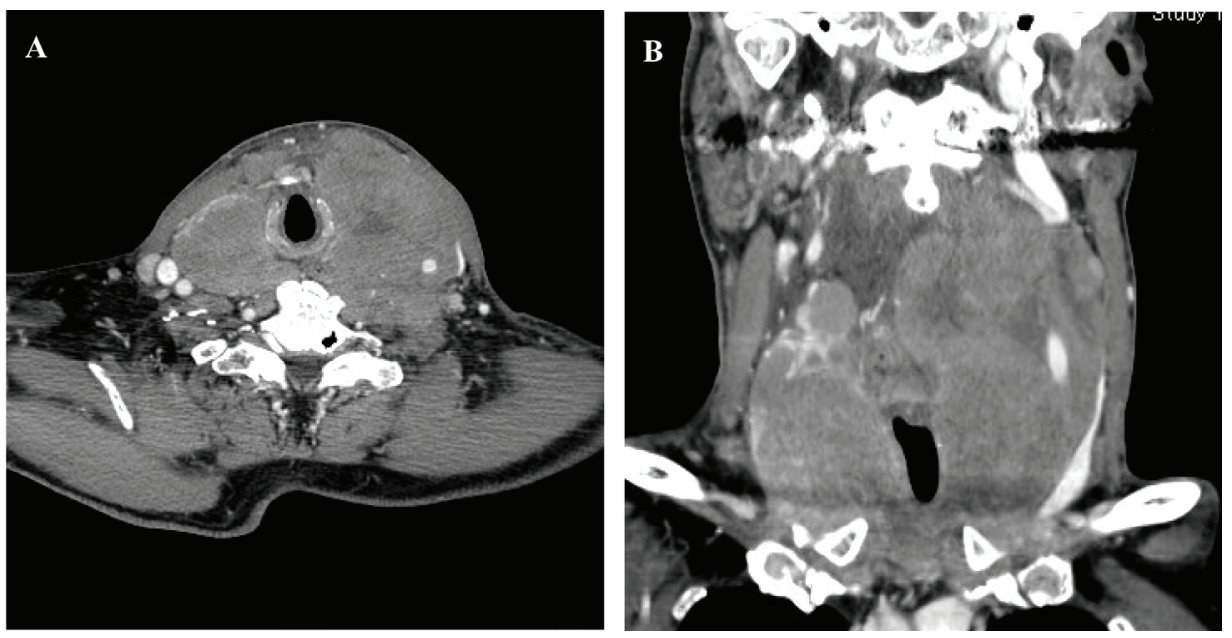

Figure 2. CT scan of the neck with enhancement revealed a large cervical mass arising from thyroid which completely encircled the narrowed trachea (A: coronal section; $B$ : transverse section).

- 3.48), free $\mathrm{T}_{4} 1.51 \mathrm{ng} / \mathrm{mL}(0.71$ - 1.85). CT scan with enhancement revealed a large cervical mass arising from thyroid which completely encircled the narrowed trachea (Fig. 2A, B). He was immediately referred to the department of endocrine surgery and under general anesthesia with endotracheal intubation, an incisional biopsy was performed for combined pathology and immunohistochemistry, that led to the diagnosis of DLBCL, with a positive immunostaining for CD10, CD20, bcl-6, but negative for MUM-1. The initial staging work-up including $\mathrm{CT}$ of the chest and abdomen and a bone marrow examination classified the patient as stage IIE based on the Ann Arbor staging classification [5] A combined chemotherapy including cyclophosphamide, doxorubicin, vincristine and prednisone plus rituximab (R-CHOP) was

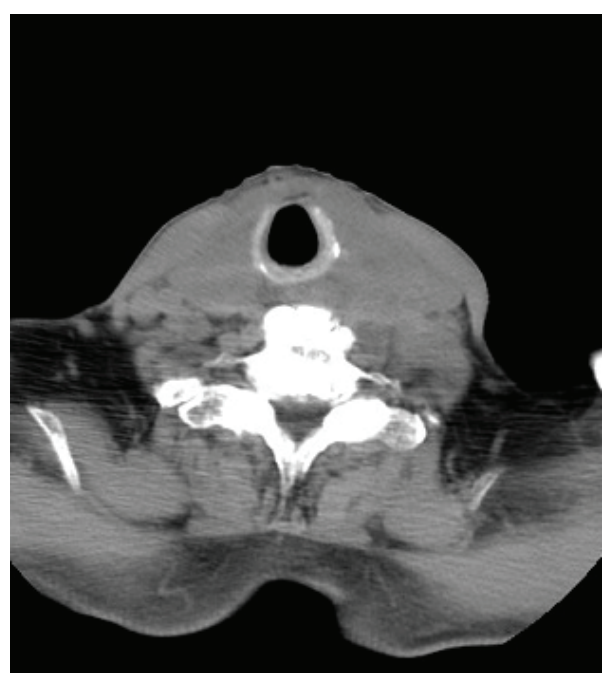

Figure 3. CT scan of the neck 3 weeks after the initiation of combination chemotherapy revealed the mass dramatically decreased in size. initiated, which dramatically shrunk the tumor (Fig. 3) and completely resolved the compression symptoms within a few days. After three courses of R-CHOP regimen followed by involved-field radiation therapy (IFRT), the patient is doing well with no recurrence.

\section{Discussion}

The association between chronic inflammatory diseases and lymphoid malignancy

Certain chronic diseases are associated with an increased risk of lymphoproliferative malignancy. Sjogren's syndrome (SS) has known for an established predisposing factor of the development of lymphoid malignancy. According to retrospective cohort studies, $9 \%$ of patients with primary SS developed malignant lymphoma [6] and about 40 times higher than that of the general population [7]. In rheumatologic diseases, rheumatoid arthritis or systemic lupus erythematosus, especially in patients with aggressive disease, is also at increased risk of developing lymphoid malignancy [8]. In addition to rheumatologic diseases, pyothorax-associated lymphoma can develop in patients with chronic pyothorax due to lung tuberculosis or tuberculous pleuritis [9] and helicobacter pylori infection is implicated in the pathogenesis of mucosa-associated lymphoid tissue (MALT) gastric lymphoma [10]. Characteristically, lymphomas associated with these chronic inflammatory conditions are predominantly B-cell origin.

\section{Epidemiology of primary thyroid lymphoma}

Primary thyroid lymphoma (PTL) is a heterogeneous disease, but the almost all cases of PTL are NHL with B-cell origin 
[4]. DLBCL and extranodal marginal zone B cell lymphoma of MALT lymphoma and coexisting both diseases are the common histologic subtypes $[4,11]$. Other less common histologic subtypes include follicular lymphoma [4, 11], Hodgkin lymphoma [4, 11], small lymphocytic lymphoma [11], T-cell lymphoma [11]. There is a 4 to 1 female predominance [11] and the median age at diagnosis is around 60 year-old $[4,11]$.

\section{The possible pathogenetic mechanism of developing PTL}

The normal thyroid gland originally has no native lymphoid tissue. Thus, PTL is considered to arise from intrathyroid lymphoid tissue acquired during the course of chronic inflammation or an autoimmune process [11]. Pre-existing HT is known for a significant predisposing factor for PTL with an estimated relative risk of 67 [12]. Up to one-half of PTL patients have a clinical history HT, and an even more patients had pathologically diagnosed with HT [11]. PTL usually develops after a long period of HT evolution as long as 20 - 30 years [13]. It has been postulated that in HT, lymphomatous change susceptible to neoplastic transformation may be due to chronic antigenic stimulation and proliferation of lymphoid tissue [14]. Recent report supports this theory by showing sequence similarity in immunoglobulin heavy chain gene rearrangement between the clonal bands of HT and that of subsequently developed PTL [15]. In addition, aberrant somatic hypermutation, previously attributed to the development of multiple proto-oncogenesis in other types of DLBCL, may constitute a pathogenetic mechanism of developing PTL by representing an early step in the process of B-cell clonal transformation in patients with HT [16].

\section{Diagnostic procedure of PTL}

PTL presents with rapidly growing mass, which can be lethal due to progressive symptoms of tracheal, laryngeal or esophageal compression [17]. Thus, early diagnosis is essential to save the patients. Fine needle aspiration (FNA) is a valuable diagnostic tool for evaluation of thyroid mass and can be the first test to diagnose PTL as it is less invasive. But, FNA accurately diagnosed PTL in only $60 \%$ of patients due to histopathological similarities between PLT and HT [11]. Thus, confirmatory procedures such as incisional biopsy are highly recommended to obtain sufficient material.

\section{The therapeutic options of PTL}

Appropriate treatment for PTL depends on histologic subtype or extent of disease. The therapeutic approach for patients with PTL has been revised over the last a few decades. Conservative treatment mainly with combination chemotherapy has replaced thyroidectomy as mainstay of therapy because effective chemotherapeutic regimens have been introduced. Nowadays, surgery is usually utilized to obtain sufficient tissue for diagnosis, not for radical therapy. For DLBCL of the thyroid, basically, treatment should be the same as DLBCL of any other site or extent. In limited DLBCL, three cycles of CHOP plus IFRT had been considered as standard treatment [18]. Recently, R-CHOP chemotherapy is the gold standard for this type of lymphoma. The addition of rituximab, a monoclonal antibody against the membrane antigen CD-20 found on pre-B and matured B lymphocytes, led to significant improvement in event-free and overall survival (OS) when compared with CHOP alone [19]. Even in patients with severe airway compromise, the tumor can be expected to shrink, which provides symptomatic relief, briefly after initiation of combination chemotherapy [20]. In limited DLBCL, there are no large randomized trials of $\mathrm{R}$-CHOP plus radiation therapy, while, in phase II study of limited DLBCL, three cycles of R-CHOP plus IFRT led to better outcome of progression-free survival (PFS) and OS at 2 and 4 years when compared with three cycles of CHOP plus IFRT [21].

\section{Our comments of the present case}

The prognosis of patients with DLBCL has been estimated using the International Prognostic Index (IPI) (age $>60$, stage III/IV disease, elevated LDH level, Eastern Cooperative Oncology Group performance status $\geq 2$, more than one extranodal site of disease) [22]. As the present case had an IPI score of 2, he was assigned into 'low-intermediate' group, indicating his 4-year OS of $81 \%$ with R-CHOP therapy [23]. According to revised IPI (R-IPI) which is on the basis of the same parameters but grouped differently as conventional IPI, the present case was assigned into 'good' group, indicating his 4-year OS of 79\% with R-CHOP therapy [23].

Recently, immunohistochemical expression of CD10, bcl-6, or MUM1 could classify DLBCL into prognostically significant subgroup with germinal center B-cell(GCB) and non-GCB, and 5-year OS with an anthracycline-containing chemotherapy regimen are $92 \%$ in $\mathrm{GCB}$, and $44 \%$ in nonGCB, respectively [24]. In this patient, CD10 and bcl-6, both are GCB markers, were positive results predictive of better OS.

Through our experience obtained from the present case, it should be emphasized that PTL is entirely different from follicular epithelial-derived thyroid malignancy in disease management, and if PTL is clinically suspected, an incisional biopsy of the thyroid grand is highly recommended because combined pathology and immunohistochemistry can aid in confirmation of histopathology or histologic subtypes, making therapeutic planning, and predicting prognosis of the patients.

\section{Conclusion}

In patients with rapidly growing thyroid causing progressive 
compression symptoms, PTL with B-cell origin should be highly suspected. HT is a significant predisposing factor for PTL. An incisional biopsy of the thyroid grand is highly recommended for combined pathology and immunohistochemistry, which can aid in confirmation of histopathology or histologic subtypes, making therapeutic planning, and predicting prognosis of the patients. In DLBCL of the thyroid, basically, treatment is the same manner as DLBCL of any other site or extent. R-CHOP chemotherapy is a therapeutic mainstay and can dramatically shrink the tumor and briefly resolve the compression symptoms.

\section{Grant Support}

None.

\section{References}

1. Nix P, Nicolaides A, Coatesworth AP. Thyroid cancer review 2: management of differentiated thyroid cancers. Int J Clin Pract. 2005;59(12):1459-1463.

2. Nix PA, Nicolaides A, Coatesworth AP. Thyroid cancer review 3: management of medullary and undifferentiated thyroid cancer. Int J Clin Pract. 2006;60(1):80-84.

3. Anderson T, Chabner BA, Young RC, Berard CW, Garvin AJ, Simon RM, DeVita VT, Jr. Malignant lymphoma. 1. The histology and staging of 473 patients at the National Cancer Institute. Cancer. 1982;50(12):2699-2707.

4. Thieblemont C, Mayer A, Dumontet C, Barbier Y, Callet-Bauchu E, Felman P, Berger F, et al. Primary thyroid lymphoma is a heterogeneous disease. J Clin Endocrinol Metab. 2002;87(1):105-111.

5. Carbone PP, Kaplan HS, Musshoff K, Smithers DW, Tubiana M. Report of the Committee on Hodgkin's Disease Staging Classification. Cancer Res. 1971;31(11):18601861.

6. Zufferey P, Meyer OC, Grossin M, Kahn MF. Primary Sjogren's syndrome (SS) and malignant lymphoma. A retrospective cohort study of 55 patients with SS. Scand J Rheumatol. 1995;24(6):342-345.

7. Lazarus MN, Robinson D, Mak V, Moller H, Isenberg DA. Incidence of cancer in a cohort of patients with primary Sjogren's syndrome. Rheumatology (Oxford). 2006;45(8):1012-1015.

8. Carsons S. The association of malignancy with rheumatic and connective tissue diseases. Semin Oncol. 1997;24(3):360-372.

9. Aozasa K. Pyothorax-associated lymphoma. J Clin Exp Hematop. 2006;46(1):5-10.

10. Hussell T, Isaacson PG, Crabtree JE, Spencer J. The response of cells from low-grade B-cell gastric lymphomas of mucosa-associated lymphoid tissue to
Helicobacter pylori. Lancet. 1993;342(8871):571-574.

11. Hwang YC, Kim TY, Kim WB, Shong YK, Yi KH, Shong $\mathrm{M}$, Jo YS, et al. Clinical characteristics of primary thyroid lymphoma in Koreans. Endocr J. 2009;56(3):399405.

12. Holm LE, Blomgren H, Lowhagen T. Cancer risks in patients with chronic lymphocytic thyroiditis. N Engl J Med. 1985;312(10):601-604.

13. Pedersen RK, Pedersen NT. Primary non-Hodgkin's lymphoma of the thyroid gland: a population based study. Histopathology. 1996;28(1):25-32.

14. Graff-Baker A, Sosa JA, Roman SA. Primary thyroid lymphoma: a review of recent developments in diagnosis and histology-driven treatment. Curr Opin Oncol. 2010;22(1):17-22.

15. Moshynska OV, Saxena A. Clonal relationship between Hashimoto thyroiditis and thyroid lymphoma. J Clin Pathol. 2008;61(4):438-444.

16. Takakuwa T, Miyauchi A, Aozasa K. Aberrant somatic hypermutations in thyroid lymphomas. Leuk Res. 2009;33(5):649-654.

17. Matsuzuka F, Miyauchi A, Katayama S, Narabayashi I, Ikeda H, Kuma K, Sugawara M. Clinical aspects of primary thyroid lymphoma: diagnosis and treatment based on our experience of 119 cases. Thyroid. 1993;3(2):93-99.

18. Miller TP, Dahlberg S, Cassady JR, Adelstein DJ, Spier CM, Grogan TM, LeBlanc M, et al. Chemotherapy alone compared with chemotherapy plus radiotherapy for localized intermediate- and high-grade non-Hodgkin's lymphoma. N Engl J Med. 1998;339(1):21-26.

19. Coiffier B, Lepage E, Briere J, Herbrecht R, Tilly H, Bouabdallah R, Morel P, et al. CHOP chemotherapy plus rituximab compared with $\mathrm{CHOP}$ alone in elderly patients with diffuse large-B-cell lymphoma. N Engl J Med. 2002;346(4):235-242.

20. Sarinah B, Hisham AN. Primary lymphoma of the thyroid: diagnostic and therapeutic considerations. Asian J Surg. 2010;33(1):20-24.

21. Persky DO, Unger JM, Spier CM, Stea B, LeBlanc M, McCarty MJ, Rimsza LM, et al. Phase II study of rituximab plus three cycles of CHOP and involved-field radiotherapy for patients with limited-stage aggressive Bcell lymphoma: Southwest Oncology Group study 0014. J Clin Oncol. 2008;26(14):2258-2263.

22. A predictive model for aggressive non-Hodgkin's lymphoma. The International Non-Hodgkin's Lymphoma Prognostic Factors Project. N Engl J Med. 1993;329(14):987-994.

23. Sehn LH, Berry B, Chhanabhai M, Fitzgerald C, Gill $\mathrm{K}$, Hoskins $\mathrm{P}$, Klasa $\mathrm{R}$, et al. The revised International Prognostic Index (R-IPI) is a better predictor of outcome than the standard IPI for patients with diffuse large B-cell lymphoma treated with R-CHOP. Blood. 2007;109(5):1857-1861. 
24. Alacacioglu I, Ozcan MA, Ozkal S, Piskin O, Turgut N, Demirkan F, Ozsan GH, et al. Prognostic significance of immunohistochemical classification of diffuse large B-cell lymphoma. Hematology. 2009;14(2):84-89. 